\title{
Adult Attachment, Emotion Dysregulation, and Symptoms of Depression and Generalized Anxiety Disorder
}

\author{
Anna Marganska, Michelle Gallagher, and Regina Miranda \\ Hunter College, City University of New York
}

\begin{abstract}
Differences in attachment style have been linked to both emotion regulation and psychological functioning, but the emotion regulatory mechanism through which attachment style might impact symptoms of depression and anxiety is unclear. The present study examined the explanatory role of emotion dysregulation in the relation between adult attachment style and symptoms of depression and generalized anxiety disorder (GAD) in a sample of 284 adults. Secure attachment was associated with lower depression and GAD symptoms and lower emotion dysregulation, whereas insecure attachment styles were generally associated with higher depression and GAD scores and higher emotion dysregulation. Perceived inability to generate effective emotion regulation strategies mediated the relation between insecure attachment and both depression and GAD symptoms. Nonacceptance of negative emotions and inability to control impulsive behaviors emerged as additional mediators of the relation between insecure attachment styles and GAD symptoms. The differential contribution of attachment style and emotion regulation to the prediction of depression and GAD symptoms may reflect differences in vulnerability to depression and GAD.
\end{abstract}

$\mathbf{R}$ elationship styles are rooted in experiences and attachment bonds with caregivers (Cassidy, 1994; Mikulincer, Shaver, \& Pereg, 2003). Attachment style may be linked to differences in emotion regulation (e.g., Gillath, Bunge, Shaver, Wendelken, \& Mikulincer, 2005; Kerns, Abraham, Schlegelmilch, \& Morgan, 2007), and chronic use of certain emotion regulation strategies is associated with specific psychological outcomes, such as depression and anxiety symptoms (Aldao, Nolen-Hoeksema, \& Schweizer, 2010; Gross \& John, 2003; Mennin, Heimberg, Turk, \& Fresco, 2005). It is less clear, however, whether emotion regulation difficulties help explain the relation between attachment style and emotional functioning. This study sought to examine how emotion regulation difficulties impact the relation between adult attachment and symptoms of depression and generalized anxiety disorder (GAD).

\section{Conceptualizing and Measuring Adult Attachment}

Drawing upon models of childhood attachment (e. g., Bowlby, 1982/1969), research on adult attachment styles has con-

This work was funded, in part, by the Hunter College Gender Equity Project, NSF ADVANCE Institutional Transformation Award 0123609. The authors thank Valerie Khait, Monique Fontes, Cary Chu, Dana Eiss, Lisa Lerner, Shama Goklani, and Alex Scilletta for their assistance with data collection, along with J. Blake Turner and Michelle Yakobson for comments on a previous draft of this article.

Correspondence concerning this article should be addressed to Regina Miranda, Department of Psychology, Hunter College, CUNY, 695 Park Ave., Room 611 HN, New York, NY 10065. Electronic mail may be sent to regina.miranda@hunter.cuny.edu. ceptualized attachment as involving the intersection between a person's image of the self and of others. Bartholomew and Horowitz's (1991) four-category model of adult attachment identifies four types of adult attachment styles. Secure attachment involves a positive view of the self and others, that is, one feels worthy of love and is comfortable being close to others. Preoccupied (or anxious/ambivalent) attachment involves a negative view of the self and a positive view of others (i.e., one feels unworthy of love but seeks others' acceptance). Fearful avoidant attachment involves a negative view of both self and others (i.e., one considers the self unworthy and expects rejection). Finally, dismissive avoidant attachment involves a positive view of the self and a negative view of others (i.e., one feels worthy yet expects others will be unavailable). This model can further be explained by a structure of anxious and avoidant behaviors (Griffin \& Bartholomew, 1994). Individuals exhibiting anxious behaviors fear abandonment and seek proximity in relationships, whereas avoidant individuals are uncomfortable with intimacy and closeness. Thus, secure attachment involves low anxiety/low avoidance; preoccupied involves high anxiety/low avoidance; fearful avoidant involves high anxiety/high avoidance; and dismissive avoidant involves low anxiety/high avoidance. While focusing on dimensions underlying attachment, this model was not meant as a comprehensive assessment of attachment styles, but rather, as a theoretical framework that might provide conceptual clarity in organizing research (Griffin \& Bartholomew, 1994).

The assessment of adult attachment has been a source of vigorous debate, as researchers endeavor to develop measures to comprehensively and accurately capture the construct, and it 
thus warrants a short discussion. Two types of assessment are commonly used in adult attachment research: the semi-structured adult attachment interview (AAI) and self-report measures, such as the Relationship Scales Questionnaire (RSQ) developed by Griffin and Bartholomew (1994). The AAI purportedly measures individuals' mental representations of attachment relationships as expressed in the coherence of their recollections of early attachment-related experiences (Hesse, 2008). In contrast, self-report measures assess how people consciously appraise and evaluate the quality of their relationships (Roisman et al., 2007). Roisman et al. (2007) found that these two types of measures were not interchangeable and suggested they might capture different underlying attachment dimensions. In the present study, we measure adult attachment via selfreport.

\section{Adult Attachment and Emotion Regulation}

Interpersonal experiences have long been thought to be a source of individual differences in affect regulation (Bowlby, 1982/1969; Mikulincer et al., 2003), and the link between attachment style and emotion regulation has since received support from research with adolescents (Cooper, Shaver, \& Collins, 1998; Sroufe, 2005), young adults (Bartholomew \& Horowitz, 1991; Roisman, Tsai, \& Chiang, 2004), and adult romantic couples (Bouthillier, Julien, Dubé, Bélanger, \& Hamelin, 2002; Feeney \& Collins, 2001).

Mikulincer et al. (2003) suggested that each adult attachment style is associated with a specific pattern of interpersonal behavior and emotion regulation when a person perceives a threat, seeks proximity to an attachment figure, and none is available. Individuals high on attachment anxiety (i.e., the preoccupied or fearful avoidant type) tend to use hyperactivating strategies, characterized by a proximity-seeking effort to elicit support, care, and attention and frequently involving clinging or controlling behaviors. Individuals high on attachment avoidance (i.e., the dismissive or fearful avoidant type) tend to use deactivating strategies, which involve denial of fear, avoidance of closeness and intimacy, and an emphasis on self-reliance and independence (Mikulincer et al., 2003). Meanwhile, securely attached individuals (low on attachment anxiety and avoidance) tend to have optimistic beliefs about their ability to handle distress (Mikulincer \& Orbach, 1995) in parallel with their acceptance of negative aspects of the self (Mikulincer, 1995). They believe others are trustworthy and reliable (Griffin \& Bartholomew, 1994) and are comfortable seeking support from others when their emotional resources are insufficient (Mikulincer et al., 2003). Securely attached individuals are also flexible in their expression of emotions and impulses in response to situational demands (Kobak \& Sceery, 1988; Sroufe, 2005). Their sense of self-efficacy and their ability to acknowledge and effectively manage negative emotions promote both interpersonal competence (Sroufe, 2005) and successful social adjustment (Cooper et al., 1998). In contrast, insecurely attached individuals exhibit lower self-esteem and social competence (Cooper et al., 1998; Sroufe, 2005) and increased loneliness and interpersonal problems (Kobak \& Sceery, 1988; Wei, Vogel, Ku, \& Zakalik, 2005).

\section{Adult Attachment, Depression, and GAD}

Although secure attachment is associated with positive psychological adjustment, insecure adult attachment has been linked to both depression and anxiety symptoms. Avoidant and anxious attachment have both been shown to be concurrently related to depressive symptoms (e.g., Mickelson, Kessler, \& Shaver, 1997; Tasca et al., 2009), with some studies suggesting that anxious attachment may be more strongly associated with depression than is avoidant attachment (e.g., Cooper et al., 1998; Wei, Mallinckrodt, Larson, \& Zakalik, 2005). Avoidant and anxious attachment have also been found to prospectively predict depressive symptoms at both 8-week and 2-year followup (Hankin, Kassel, \& Abela, 2005). Few studies, however, have focused on specific insecure attachment styles. Preoccupied and fearful individuals report more depressive symptoms than those with secure and dismissive styles (Simonelli, Ray, \& Pincus, 2004), whereas longitudinal studies show that only the fearful style is associated with a new episode of major depression (Bifulco et al., 2006) and with a greater severity of depressive symptoms (Conradi \& de Jonge, 2009) at 3-year follow-up.

Insecure adult attachment is also associated with symptoms of anxiety, including GAD. Several studies have shown that both anxious and avoidant attachment are positively associated with anxiety symptoms (Cooper, Rowe, Penton-Voak, \& Ludwig, 2009; Cooper et al., 1998), and that anxious attachment (but not avoidant attachment) prospectively predicts anxiety symptoms at 2-year follow-up (Hankin et al., 2005). Researchers have also found that both avoidant and anxious attachment are associated with a lifetime GAD diagnosis (Mickelson et al., 1997). However, there is limited research focusing on specific insecure attachment styles. Simonelli et al. (2004) found that individuals with fearful, preoccupied, and dismissive attachment reported more anxiety symptoms than securely attached individuals, whereas Bifulco et al. (2006) showed that only the angry-dismissive style was associated with a new episode of GAD at 3-year follow-up.

\section{Emotion Regulation, Depression, and GAD}

Emotion regulation - a term that has been inconsistently defined and applied (see Cole, Martin, \& Dennis, 2004, for a discussion) - has been conceptualized as a repertoire of strategies that individuals can use to enhance or suppress their emotional experience (Gross, 1998). Recent research links specific emotion regulation strategies with specific mood-related problems. Dennis (2007) found cognitive reappraisal (a shift in thinking about a future event to either neutralize its expected negative emotional impact or to enhance its positive emotional impact) and expressive suppression (inhibition of an already activated emotional response) to be associated with trait anxiety and depressed mood in a sample of healthy adults. Gross and John (2003) found that the use of reappraisal was associated with lower negative affect and better interpersonal functioning, while the use of suppression was associated with greater negative affect and poorer interpersonal functioning. Suppression appears to be a habitual and spontaneous response among individuals vulnerable to depression (Ehring, TuschenCaffier, Schnülle, Fischer, \& Gross, 2010). A recent meta-analysis 
found that three regulatory strategies were more strongly related to anxiety and depression than to other disorders: rumination (a repetitive focus on the causes and consequences of one's negative mood), reappraisal difficulties, and emotional avoidance (Aldao et al., 2010). Thus, there may be unique relations between specific emotion regulation techniques and certain psychological problems (Aldao et al., 2010).

Emotion regulation has also been defined as encompassing the awareness, understanding, and acceptance of emotions; the ability to control impulsive behaviors; behavior in accordance with desired goals when experiencing negative emotions; and the flexible use of appropriate emotion regulation strategies to meet situational requirements (Gratz \& Roemer, 2004). Emotion dysregulation, conceptualized as comprising difficulties in each of these domains, has been linked to various psychological problems, including social anxiety (Mennin, McLaughlin, \& Flanagan, 2009; Turk, Heimberg, Luterek, Mennin, \& Fresco, 2005), panic disorder (Tull, Stipelman, Salters-Pedneault, \& Gratz, 2009), deliberate self-harm (Slee, Garnefski, Spinhoven, \& Arensman, 2008), and posttraumatic stress symptoms (Tull, Barrett, McMillan, \& Roemer, 2007).

Researchers have also looked at these six emotion regulation aspects in relation to GAD and depression. College students with GAD have been found to be less accepting of and, to have a poorer understanding of their emotions and also to perceive themselves as less capable of selecting effective regulatory strategies compared to those who do not meet criteria for GAD (Mennin et al., 2005, 2009). GAD is also associated with less clarity about one's emotions as well as a reduced ability to control one's behavior or to achieve one's goals when distressed (Salters-Pedneault, Roemer, Tull, Rucker, \& Mennin, 2006). Meanwhile, compared to never-depressed individuals, recovered depressed individuals report that they are less able to control their behavior, to select effective regulatory strategies, or to achieve their goals when distressed (Ehring, Fischer, Schnülle, Bösterling, \& Tuschen-Caffier, 2008).

One study that examined these six regulatory aspects in the context of both depression and GAD found that perceived inability to effectively use regulation strategies uniquely predicted GAD, whereas poor understanding of emotions uniquely predicted depression (Mennin, Holaway, Fresco, Moore, \& Heimberg, 2007). Given a high co-occurrence of depression and GAD (Kessler et al., 1996), attributed to a shared component of negative affect (see Anderson \& Hope, 2008, for a review), research should try to tease apart aspects of emotion regulation that jointly or separately contribute to these disorders.

\section{The Present Study}

Prior research attests to the link between attachment patterns and individual differences in emotion regulation, between insecure attachment styles and symptoms of depression and GAD, and to the relation between emotion regulation and depression and GAD symptoms. However, the mechanism through which attachment style and emotion regulation influence depression and anxiety symptoms is not well understood. In one study that examined these pathways, Wei, Vogel, et al. (2005) found that affect regulation mediated the relation between attachment style and negative mood. Moreover, there were distinct patterns of mediation, such that emotional reactivity fully mediated the link between anxious attachment and negative mood, whereas emotional detachment fully mediated the relation between avoidant attachment and negative mood. Similarly, Tasca et al. (2009) showed that emotional reactivity mediated the relation between attachment anxiety and depression symptoms, whereas emotional deactivation mediated the relation between attachment avoidance and depression symptoms.

The present study sought to examine the explanatory role of emotion dysregulation in the relation between attachment styles and symptoms of depression and GAD using data collected as part of another study (Miranda, Fontes, \& Marroquín, 2008). First, we predicted that individuals who identified themselves as securely attached in their adult relationships would show more effective emotion regulation (or lower emotional dysregulation) in each of six dimensions-awareness, understanding and acceptance of emotions, ability to control impulsive behaviors, behavior in accordance with desired goals, and the ability to flexibly use situation-appropriate emotion regulation strategies. We further predicted that this effective regulation would be associated with lower depression and GAD symptoms. In contrast, we expected that insecure attachment would be associated with greater emotional dysregulation and with higher symptoms of depression and GAD. We expected that emotion regulation would statistically mediate the relation between attachment styles and symptoms of both depression and GAD, and we wished to explore which forms of emotion dysregulation would best explain these relations. On the basis of previous research (Ehring et al., 2008; Mennin et al., 2005, 2007, 2009; SaltersPedneault et al., 2006), we expected that lack of emotional clarity, as well as the perceived inability to control one's behavior, to achieve one's goals, or to effectively select emotion regulation strategies when distressed, might mediate the relation between insecure attachment styles and symptoms of both depression and GAD. We also expected that lack of acceptance of emotions would specifically mediate the relation between insecure attachment styles (specifically, fearful avoidant attachment) and GAD symptoms.

\section{Method}

\section{Participants}

Participants were college undergraduates in an ethnically diverse public college in the northeastern United States. Participants $(N=284 ; 230$ female and 54 male) completed a packet of self-report measures as part of a research participation requirement in their Introduction to Psychology courses. Ages ranged from 18 to $48(M=20.5, S D=4.8)$, and participants reported their race or ethnic membership as White (35\%), Asian $(26 \%)$, Hispanic (18\%), Black (14\%), and other (7\%).

\section{Measures}

The Difficulties in Emotion Regulation Scale. The Difficulties in Emotion Regulation Scale (DERS; Gratz \& Roemer, 2004) is a 36-item self-report measure designed to assess six clinically relevant difficulties in emotion regulation in 
response to distress: nonacceptance of negative emotions (Nonacceptance), difficulties engaging in goal-directed behavior (Goals), difficulties refraining from impulsive behavior (Impulse), lack of awareness of emotional responses (Awareness), the belief that one has limited access to effective emotion regulation strategies (Strategies), and lack of clarity about the emotions that one is experiencing (Clarity). Each item is scored on a 5-point Likert scale, ranging from 1 (almost never) to 5 (almost always). Higher scores indicate greater difficulties with emotion regulation. Average scores were computed to allow comparison across scales, given that each scale consisted of a different number of items. The DERS has high internal consistency $(\alpha=.93)$ with Cronbach's $\alpha>.80$ for each subscale and good construct validity, with correlations among factors ranging from $r=.14$ to $r=.63$ (Gratz \& Roemer, 2004).

The Relationship Scales Questionnaire. The RSQ (Griffin \& Bartholomew, 1994) is a 30-item self-report measure assessing four adult attachment styles. Each item is scored on a 5-point Likert scale, ranging from 1 (not at all like me) to 5 (very much like me). The scale reflects characteristics of close relationships and differentiates between secure, preoccupied (anxiousambivalent), fearful avoidant, and dismissive avoidant styles along the dimensions of anxious and avoidant attachment-related behaviors, as per Bartholomew and Horowitz's (1991) four-category model of adult attachment. The measure has shown both discriminant and convergent validity (Griffin \& Bartholomew, 1994). For the present study, scores on the four attachment styles were obtained by averaging items on each of the RSQ subscales, given that each scale is comprised of a different number of items. The four styles have modest individual internal consistency reliabilities, but the set has been determined useful for assessing attachment styles in adults and adolescents (see Dinero, Conger, Shaver, Widaman, \& Larsen-Rife, 2008, for a discussion).

The Beck Depression Inventory, Second Edition. The Beck Depression Inventory, Second Edition (BDI-II; Beck, Steer, \& Brown, 1996) is a 21-item self-report questionnaire that measures various symptoms of depression, including loss of pleasure, sadness, and changes in sleep, appetite, energy levels, and concentration within the previous 2 weeks. Each item of the self-report is scored on a 4-point Likert scale ranging from 0 (e.g., I do not feel sad) to 3 (e.g., I feel so sad or unhappy that I can't stand it), with total scores ranging from 0 to 63. The measure has been found to have good test-retest reliability $(r=.91$ to $r=.93)$ in college-student samples and good predictive, convergent, and divergent validity in clinical and nonclinical samples (Beck et al., 1996; Dosois, Dobson, \& Ahnberg, 1998; Whisman, Perez, \& Ramel, 2000). The BDI-II showed high internal consistency in the present sample $(\alpha=.88)$, and average scores were in the minimal range $(M=11.9, S D=8.1)$, but ranged from no symptoms (score of 0) to clinically significant symptoms (score of 38 ).

The Generalized Anxiety Disorder QuestionnaireIV (GAD-Q-IV). The GAD-Q-IV (Newman et al., 2002) is a nine-item self-report instrument assessing symptoms reflecting DSM-IV criteria for GAD (APA, 1994). The questions reflect the presence or absence of excessive or uncontrollable worry within the last 6 months, as well as accompanying physical symptoms, such as restlessness, sleep disturbances, irritability, or muscle tension. The GAD-Q-IV can be scored for a diagnosis, with a score above 5.7 indicative of clinically significant GAD symptoms. In the present study, the measure was scored continuously using a sum total, with scores ranging from 0 to $13(M=5.8, S D=3.2)$ and had high internal consistency $(\alpha=.80)$. The GAD-Q-IV has been found to have good convergent validity with a GAD diagnosis based on a diagnostic interview to discriminate between GAD and panic disorder and social phobia diagnoses and to demonstrate good test-retest reliability over a 2-week period (Newman et al., 2002).

\section{Procedure}

Participants completed a battery of self-report measures that included the DERS, RSQ, BDI-II, and GAD-Q-IV in small groups of two to eight individuals. Participants received credit toward their research participation requirement in their introductory psychology class for completion of the measures.

\section{Results}

\section{Differences by Age, Gender, and Race or Ethnicity}

There were generally no statistically significant differences in scores on study variables by gender and race or ethnicity, with one exception: There was a statistically significant omnibus difference in dismissive attachment by race or ethnicity, $F(4$, $278)=2.60, p<.05$, but post hoc $t$ tests with Bonferroni corrections for multiple comparisons revealed no significant differences between groups. Age was not significantly associated with any of the variables, except fearful and preoccupied attachment, which were negatively correlated with age $(r=-.16$ and -.17 , respectively, $p<.01)$. As age, gender, and race or ethnicity were not significantly associated with symptoms of depression or GAD, nor did adjusting for these variables impact the overall direction of the findings, analyses are presented without adjusting for these variables.

\section{Attachment Styles, DERS Scales, and Depression and GAD Symptoms}

Means and standard deviations, along with correlations, are presented in Table 1. Secure attachment was significantly and negatively correlated with measures of depression and GAD. Secure attachment was also significantly and negatively related to all six emotion dysregulation scales. In contrast with secure attachment style, fearful avoidant and preoccupied attachment styles were significantly and positively correlated with all measures of emotion dysregulation except Awareness, and with both depression and GAD symptoms. However, the dismissive avoidant style was significantly correlated with depression and Nonacceptance but not with GAD or with any of the other emotion dysregulation scales. Zero-order correlations among variables are presented in Table 1 . There were no significant gender differences in participants' scores on the BDI-II, GAD-Q-IV, DERS, and RSQ. 


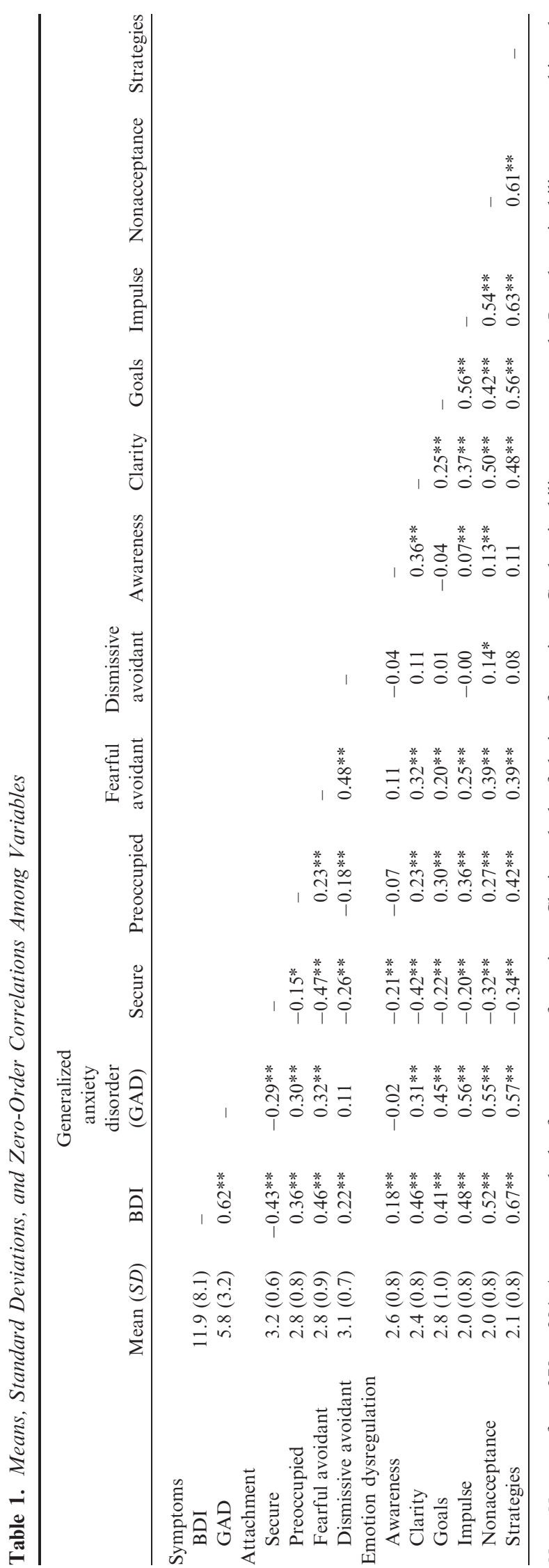

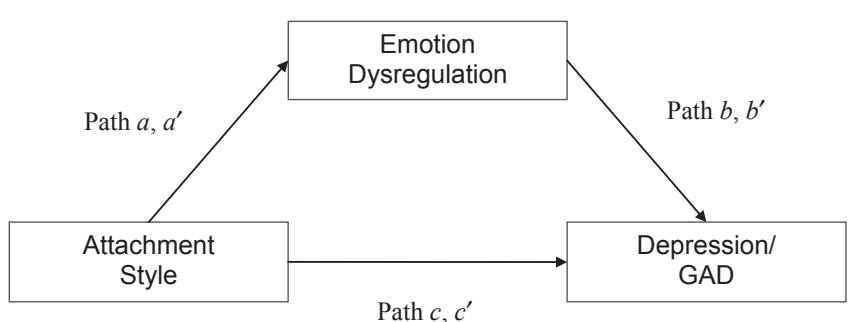

Figure 1. Mediational model for attachment style, emotion dysregulation (DERS) scales, and depression/generalized anxiety disorder (GAD) symptoms. Path $a$ reflects relation between each attachment style and emotion dysregulation, adjusting for all other attachment styles. Path $b$ reflects relation between each DERS scale and symptoms, adjusting for all other DERS scales. Path $c$ reflects relation between each attachment style and either depression or GAD symptoms, adjusting for all other attachment styles. Path $a^{\prime}$ reflects attachment-emotion dysregulation relation, adjusting both for other attachment styles and other DERS scales. Path $b^{\prime}$ reflects emotion dysregulation-symptom relation, adjusting both for attachment styles and other DERS scales. Path $c^{\prime}$ reflects the relation between each attachment style and depression or GAD symptoms after adjusting for mediators (DERS scales).

\section{Emotion Regulation as a Mediator of the Relation Between Attachment Styles and Symptoms of Depression and GAD}

Attachment styles and emotion dysregulation dimensions were examined as predictors of depression and GAD symptoms via a series of hierarchical linear regressions. Baron and Kenny's (1986) criteria were used to establish mediation (see Figure 1 for path diagram). These criteria require: (a) that the predictor variable be significantly correlated with the outcome variable (path c), (b) that the mediator be significantly correlated with both the predictor (path $a$ ) and the outcome variable (path $b$ ), and (c) that the effect of the predictor variable on the outcome variable come close to zero after controlling for the mediator (path $c^{\prime}$ ). Statistical significance of the indirect relation between attachment style and symptoms through emotion dysregulation was assessed using Sobel's $z$ test (Preacher \& Leonardelli, 2001; Sobel, 1982).

Structural equation modeling (SEM) with maximum likelihood estimation (using AMOS software) was used to build regression equations. This statistical technique allows for simultaneous testing of relations between all variables while statistically separating the overlap between the variables (Byrne, 2001). (Note that because we were not testing the fit of a particular model, fit indices are not reported). In Step 1, attachment styles were entered as predictors and depression or GAD symptoms as outcome variables to examine the relation between attachment style and either depression or GAD symptoms (see Step 1 in Tables 2 and 3). DERS scales were entered as predictors in Step 2. The use of SEM allowed for simultaneous examination of the unique relations between (a) each attachment style and each DERS scale, adjusting for other attachment styles and other DERS scales (path $a^{\prime}$ ); (b) each DERS scale and depression or GAD, adjusting for the effects of attachment styles and other DERS scales (path $b^{\prime}$ ); and (c) 
Table 2. Attachment Style, Emotion Dysregulation (DERS) Scales, and Depressive Symptoms

\begin{tabular}{|c|c|c|c|c|c|c|c|c|c|c|c|}
\hline Step & Variable & $\beta\left(\right.$ path $\left.a^{\prime}\right)$ & $t$ & $p$ & $\beta\left(\right.$ path $\left.b^{\prime}\right)$ & $t$ & $p$ & $\beta\left(\right.$ path $\left.c, c^{\prime}\right)$ & $t$ & $p$ & Sobel $z$ test \\
\hline & Preoccupied & & & & & & & $.31(c)$ & 5.99 & $* *$ & \\
\hline \multirow[t]{22}{*}{2} & Secure & & & & & & & & & & \\
\hline & Awareness & -.22 & -3.91 & $* *$ & .10 & 2.10 & $*$ & $-.13\left(c^{\prime}\right)$ & -2.56 & $* *$ & \\
\hline & Clarity & -.35 & -6.52 & $* *$ & .06 & 1.13 & $n s$ & & & & \\
\hline & Nonacceptance & -.18 & -3.22 & $* *$ & .08 & 1.65 & $n s$ & & & & \\
\hline & Strategies & -.19 & -3.67 & $* *$ & .42 & 8.30 & $* *$ & & & & $-3.34 * *$ \\
\hline & Preoccupied & & & & & & & & & & \\
\hline & Awareness & -.16 & -2.89 & $* *$ & .10 & 2.10 & $*$ & $.14\left(c^{\prime}\right)$ & 2.65 & $* *$ & \\
\hline & Clarity & .14 & 2.62 & $* *$ & .06 & 1.13 & $n s$ & & & & \\
\hline & Goals & .26 & 4.54 & $* *$ & .04 & .87 & $n s$ & & & & \\
\hline & Awareness & .13 & 2.37 & $*$ & .10 & 2.10 & $*$ & $.10\left(c^{\prime}\right)$ & 1.94 & $n s$ & \\
\hline & Clarity & .14 & 2.67 & $* *$ & .06 & 1.13 & $n s$ & & & & \\
\hline & Goals & .08 & 1.36 & $n s$ & .04 & .87 & $n s$ & & & & \\
\hline & Impulse & .17 & 2.98 & $* *$ & .06 & 1.24 & $n s$ & & & & \\
\hline & Nonacceptance & .19 & 5.10 & $* *$ & .08 & 1.65 & $n s$ & & & & \\
\hline & Strategies & .25 & 4.80 & $* *$ & .42 & 8.30 & $* *$ & & & & $4.14 * *$ \\
\hline & Dismissive avoidant & & & & & & & & & & \\
\hline & Awareness & -.18 & -3.26 & $* *$ & .10 & 2.10 & $*$ & $.14\left(c^{\prime}\right)$ & 3.00 & $* *$ & \\
\hline & Clarity & -.03 & -.48 & $n s$ & .06 & 1.13 & $n s$ & & & & \\
\hline & Goals & -.03 & -.46 & $n s$ & .04 & .87 & $n s$ & & & & \\
\hline & Impulse & -.05 & -.90 & $n s$ & .06 & 1.24 & $n s$ & & & & \\
\hline & Nonacceptance & .00 & .03 & $n s$ & .08 & 1.65 & $n s$ & & & & \\
\hline & Strategies & -.03 & -.56 & ns & .42 & 8.30 & $* *$ & & & & \\
\hline
\end{tabular}

Note. $\beta=$ Standardized regression coefficient (Beta); path $a^{\prime}=$ relation between attachment and DERS scale, adjusting for all other DERS scales; path $b^{\prime}=$ relation between DERS scale and depression symptoms, adjusting for all other DERS scales; path $c=$ attachment-depression relation, adjusting for other attachment styles; path $c^{\prime}=$ attachment-depression relation, adjusting for other attachment styles and for DERS scales.

$* p<.05 . * * p<.01$.

each attachment style and depression or GAD, adjusting for DERS scales and all other attachment styles (path $c^{\prime}$ ). Results of mediation analyses are presented in the Step 2 section of Table 2 for depression symptoms and in Table 3 for GAD symptoms.

Secure, preoccupied, and fearful avoidant attachment styles predicted both depression $(\beta=-.27, .31$, and .25 , respectively, $p<.01)$ and GAD symptoms $(\beta=-.17, .25$, and .18 , respectively, $p<.01$ ), adjusting for each other attachment style. Dismissive avoidant attachment was not a significant predictor of $\operatorname{GAD}(\beta=.03)$ and was a marginally significant predictor of depression $(\beta=.10, p=.06)$. When emotion dysregulation scales were entered in Step 2 , secure $(\beta=-.13$, $p<.01)$ and preoccupied $(\beta=.14, p<.01)$ attachment styles remained significant predictors of depressive symptoms, and dismissive avoidant attachment became a statistically significant predictor of depression symptoms $(\beta=.14, p<.01)$. However, none of the attachment styles significantly predicted symptoms of GAD after adjusting for the DERS scales. In addition, Strategies was the only emotion dysregulation scale that significantly predicted depression symptoms $(\beta=.42$, $p<.01$ ), adjusting for other DERS scales, whereas Impulse, Nonacceptance, and Strategies significantly predicted GAD symptoms.

Perceived limited access to effective emotion regulation strategies (Strategies) significantly decreased each of the relations between secure and preoccupied attachment and depression $(\beta$ decreased from -.27 to $-.13, Z_{\text {Sobel }}=-3.34, \quad p<.01 ; \beta$ decreased from .31 to $.14, Z_{\text {Sobel }}=5.13, p<.01$, respectively) and was thus a partial mediator of these relations. Strategies fully mediated the relation between fearful avoidant attachment and depression ( $\beta$ decreased from .25 to $.10, n s, Z_{\text {Sobel }}=4.14$, $p<.01$; see Table 2).

Lack of acceptance of negative emotions (Nonacceptance) and Strategies fully mediated the relation between secure and fearful avoidant attachment styles and GAD symptoms ( $\beta$ decreased from -.17 and .18 , respectively, $p<.01$, to -.10 and .04, respectively, $n s$ ), and Strategies and Impulse, or the inability to refrain from impulsive behaviors when distressed, fully mediated the relation between preoccupied attachment and GAD symptoms ( $\beta$ decreased from $.25, p<.01$, to .04 , $n s$; see Step 2 of Table 3 for tests of all indirect relations). 
Table 3. Attachment Style, Emotion Dysregulation (DERS) Scales, and Generalized Anxiety Disorder (GAD) Symptoms

\begin{tabular}{|c|c|c|c|c|c|c|c|c|c|c|c|}
\hline Step & Variable & $\beta\left(\right.$ path $\left.a^{\prime}\right)$ & $t$ & $p$ & $\beta\left(\right.$ path $\left.b^{\prime}\right)$ & $t$ & $p$ & $\beta$ (path $\left.c, c^{\prime}\right)$ & $t$ & $p$ & Sobel $z$ test \\
\hline \multirow{2}{*}{1} & Preoccupied & & & & & & & $.25(c)$ & 4.50 & $* *$ & \\
\hline & Dismissive avoidant & & & & & & & $.03(c)$ & .56 & $n s$ & \\
\hline \multirow[t]{22}{*}{2} & Secure & & & & & & & & & & \\
\hline & Awareness & -.22 & -3.91 & $* *$ & -.10 & -1.98 & $*$ & $-.10\left(c^{\prime}\right)$ & -1.70 & $n s$ & \\
\hline & Clarity & -.35 & -6.52 & $* *$ & -.04 & -.75 & $n s$ & & & & \\
\hline & Nonacceptance & -.18 & -3.22 & $* *$ & .27 & 5.09 & $* *$ & & & & $-2.36^{*}$ \\
\hline & Strategies & -.19 & -3.67 & $* *$ & .20 & 3.62 & $* *$ & & & & $-2.38^{*}$ \\
\hline & Preoccupied & & & & & & & & & & \\
\hline & Awareness & -.16 & -2.89 & $* *$ & -.10 & -1.98 & $*$ & $.04\left(c^{\prime}\right)$ & .65 & $n s$ & \\
\hline & Clarity & .14 & 2.62 & $* *$ & -.04 & -.75 & $n s$ & & & & \\
\hline & Goals & .26 & 4.54 & $* *$ & .07 & 1.28 & $n s$ & & & & \\
\hline & Awareness & .13 & 2.37 & $*$ & -.10 & -1.98 & $*$ & $.04\left(c^{\prime}\right)$ & .71 & $n s$ & \\
\hline & Clarity & .14 & 2.67 & $* *$ & -.04 & -.75 & $n s$ & & & & \\
\hline & Goals & .08 & 1.36 & $n s$ & .07 & 1.28 & $n s$ & & & & \\
\hline & Impulse & .17 & 2.98 & $* *$ & .28 & 5.26 & $* *$ & & & & -.79 \\
\hline & Nonacceptance & .19 & 5.10 & $* *$ & .27 & 5.09 & $* *$ & & & & $2.76^{* *}$ \\
\hline & Strategies & .25 & 4.80 & $* *$ & .20 & 3.62 & $* *$ & & & & $2.43^{*}$ \\
\hline & Dismissive avoidant & & 7 & & & & & & & & \\
\hline & Awareness & -.18 & -3.26 & $* *$ & -.10 & -1.98 & $*$ & $.04\left(c^{\prime}\right)$ & .70 & $n s$ & \\
\hline & Clarity & -.03 & -.48 & $n s$ & -.04 & -.75 & $n s$ & & & & \\
\hline & Goals & -.03 & -.46 & $n s$ & .07 & 1.28 & $n s$ & & & & \\
\hline & Impulse & -.05 & -.90 & $n s$ & .28 & 5.26 & $* *$ & & & & \\
\hline & Nonacceptance & .00 & .03 & ns & .27 & 5.09 & $* *$ & & & & \\
\hline & Strategies & -.03 & -.56 & $n s$ & .20 & 3.62 & $* *$ & & & & \\
\hline
\end{tabular}

Note. $\beta=$ Standardized regression coefficient (Beta); path $a^{\prime}=$ relation between attachment and DERS scale, adjusting for all other DERS scales; path $b^{\prime}=$ relation between DERS scale and GAD symptoms, adjusting for all other DERS scales; path $c=$ attachment-GAD relation, adjusting for other attachment styles; path $c^{\prime}=$ attachment-GAD relation, adjusting for other attachment styles and for DERS scales.

$* p<.05 . * * p<.01$.

\section{Discussion}

This study explored the relation between attachment style, emotion dysregulation, and symptoms of depression and GAD. As predicted, secure attachment style was inversely related to depression and GAD symptoms and to all emotion dysregulation scales, indicating that individuals who scored high on attachment security had greater confidence in being able to manage their emotions. They were also more able to stay focused on goals, to control impulsive behaviors, and to distinguish, acknowledge, and accept their emotions during times of adversity. These results accord with previous research establishing secure attachment as a foundation for effective emotion regulation and linking successful emotion regulation with better psychosocial outcomes (Cooper et al., 1998; Kobak \& Sceery, 1988; Sroufe, 2005). In contrast, insecure attachment styles generally showed positive associations with emotion dysregulation and with symptoms of both depression and GAD, suggesting that attachment insecurity may promote ineffective emotion regulation and thus increase risk for these disorders.
Fearful avoidant and preoccupied attachment emerged as the attachment styles most strongly associated with both depression and GAD symptoms. This finding is consistent with research showing that these attachment styles - which are characterized by attachment anxiety-are concurrently and prospectively linked to both depression and anxiety (Hankin et al., 2005; Simonelli et al., 2004). Meanwhile, dismissive attachment, which is characterized by attachment avoidance, was associated with only depression. Thus, our results are similar to those of Hankin et al. (2005), who found that avoidant attachment predicted only depression, whereas anxious attachment predicted both depression and anxiety. The anxious dimension of attachment may be a nonspecific risk factor for dysphoria and may help to account for the high comorbidity of depression and anxiety (Hankin et al., 2005).

Interpersonal accounts of GAD may help to explain its relationship with the fearful avoidant and preoccupied attachment styles. Both styles are characterized by hyperactivating emotion regulation strategies that involve increased monitoring of threats to the self, especially social threats such as abandonment 
(Mikulincer et al., 2003). Similarly, individuals with GAD show an attentional bias to threatening faces (Mogg, Millar, \& Bradley, 2000) as well as relational hypervigilance (Gasperini, Battaglia, Diaferia, \& Bellodi, 1990). Individuals with GAD also report that their worry-related cognitions are most often focused on interpersonal domains, such as conflict and social acceptance (Breitholtz, Johansson, \& Öst, 1999). Furthermore, the hyperactivating strategies used by preoccupied and fearful individuals frequently involve attempts to elicit care and attention from others, often through clinging behaviors (Mikulincer et al., 2003). Research suggests that GAD is associated with a similar tendency to excessively seek reassurance from others (Cougle et al., 2012), perhaps as a means to alleviate worryrelated distress.

Fearful avoidant and preoccupied attachment were also the styles most strongly linked with emotion dysregulation. Gillath et al. (2005) suggest that individuals with high scores on attachment anxiety “...experience negative emotions intensely, have greater access to a web of negative memories, and find it difficult to suppress negative feelings" (p. 844). Unable to reduce their intense feelings of distress in other ways, these individuals may turn to maladaptive cognitive strategies (Gillath et al., 2005). We also found that the fearful avoidant and preoccupied styles were most strongly associated with the same emotion regulation domain: the perceived inability to employ effective regulatory strategies (Strategies). Another shared characteristic of these styles is a negative view of the self, and this negative selfconcept may lead these individuals to feel less confident about their ability to manage distress.

Dismissive avoidant style had the weakest relation with all measures of psychopathology and emotion dysregulation. Individuals with avoidant attachment styles have been found to respond to distress by using deactivating strategies, such as disengagement from feelings and from potential social support (Mikulincer et al., 2003), and this inclination may lead them to have a biased view of their own emotions and emotion regulation competency (Kobak \& Sceery, 1988), making it difficult to accurately assess these domains. Nevertheless, dismissive avoidant attachment was associated with Nonacceptance of negative emotions in keeping with a tendency to actively dismiss or ignore one's feelings (Mikulincer et al., 2003).

Despite their seemingly neutral emotional responses, dismissive individuals have been shown to experience distress, as measured by physiological indices such as heart rate, skin conductance, and plasma cortisol (Roisman et al., 2004; also see Cassidy, 1994, for a discussion). In light of these findings, our study's limited ability to detect significant relations between dismissive avoidant attachment and most measures likely resulted from a reliance on self-report measures and the use of a restricted number of emotion regulation domains. As a result, we may not have been able to capture the full repertoire of emotion regulation techniques used by dismissive individuals. However, given that we found dismissive attachment to be associated with symptoms of depression, and prior research has found it to be associated with GAD (Bifulco et al., 2006), it is important that future studies examine emotion regulation in these individuals, perhaps via observer-rated or skills-based assessment.
We had also set out to determine whether emotion dysregulation statistically mediated the relation between attachment styles and symptoms of either depression or GAD. The analyses revealed that individuals' perceived inability to harness effective emotion regulation strategies (Strategies) partially mediated the relation between secure and preoccupied attachment styles and symptoms of depression and fully mediated the relation between fearful avoidant attachment and depression. However, the relations were different for GAD, where additional mediators emerged. In addition to Strategies, which fully mediated the relation between secure, preoccupied, and fearful avoidant attachment styles and GAD symptoms, Impulse also fully mediated the relation between preoccupied attachment and GAD. Nonacceptance fully mediated the relation between both secure and fearful avoidant attachment and GAD.

\section{Implications for the Distinction Between Depression and GAD Symptoms}

The differing mediation patterns found in these data may reflect differences in vulnerability to depression and GAD symptoms. Perceived inability to manage emotional responses (Strategies) appears to be most implicated in the relation between attachment styles and depression symptoms. Prior research suggests that anxious attachment (linked to fearful avoidant and preoccupied styles) is associated with a tendency to experience negative cognitions, such as rumination, in response to negative events, and with an absence of positive cognitions in response to positive events (see Gentzler, Kerns, $\&$ Keener, 2010). Perhaps an intense focus on negative experiences leads individuals to perceive themselves as unable to effectively manage their emotions and thus increases their vulnerability to depression, which is associated with a combination of high negative affect and low positive affect (Clark \& Watson, 1991).

Strategies fully mediated the relation between fearful avoidant attachment and depression symptoms. Individuals with avoidant attachment appear to use suppression as a predominant emotion regulation technique (Gross \& John, 2003), and suppression has been linked to both greater negative affect (Gross \& John, 2003) and depression vulnerability (Ehring et al., 2010). Gross and John (2003) reason that suppressors, because they do not acknowledge or express their negative emotions and thus deprive themselves of the cognitive resolution and social support that might alleviate their distress, are more likely to ruminate (i.e., to focus on symptoms, self, and the causes and consequences of their depressed mood). Such rumination may, in turn, contribute to increases in symptoms of depression over time (NolenHoeksema, Larson, \& Grayson, 1999).

The Strategies domain also partially mediated the link between preoccupied attachment and depression symptoms. Those with preoccupied attachment tend to hold a negative view of the self and a positive view of others (Griffin \& Bartholomew, 1994) and have more self-doubt (Hazan \& Shaver, 1987). They thus tend to exaggerate the appraisal of threats to elicit attention or support (Mikulincer et al., 2003) even as they fail to modulate negative affect and impulsive behavior within socially acceptable boundaries (Cooper et al., 1998). The dependency on others in tandem with an intrusive and controlling 
interpersonal style (Feeney \& Collins, 2001) may present more opportunities for, and greater likelihood of, rejection. This rejection may, in turn, intensify preoccupation with others' approval, facilitating depression symptoms.

Our findings for GAD symptoms were more complex and add further support to a growing line of research implicating emotion dysregulation in the development and maintenance of GAD. Mennin et al. (2005) developed and tested a model of GAD that incorporates the following emotion regulation deficits: (a) greater intensity of emotions, (b) poorer understanding of emotions, (c) more fear of and negative reactivity to emotions, and (d) more difficulty managing emotions. Subsequent research has largely verified these deficits (Mennin et al., 2009; Salters-Pedneault et al., 2006; Turk et al., 2005). Because of these deficits, individuals with GAD may experience their feelings as particularly intense, confusing, and aversive and may use worry to avoid these emotions (Borkovec, Alcaine, \& Behar, 2004; Mennin et al., 2005).

We found that Strategies fully mediated the relation between preoccupied and fearful avoidant attachment and GAD symptoms. The use of worry as a maladaptive strategy for avoiding distressing emotions may partially account for this finding. However, researchers have also suggested that individuals with GAD may engage in a more general experiential avoidance, in which they maladaptively attempt to avoid all internal experiences, including thoughts, sensations, and feelings (Roemer, Salters, Raffa, \& Orsillo, 2005). As Strategies can be interpreted as a measure of confidence in one's ability to regulate emotions, our finding is also consistent with evidence that individuals with GAD have more difficulty believing that they are able to modulate their emotions (Mennin et al., 2005).

Inability to control behavior in response to negative emotions (Impulse) fully mediated the relation between preoccupied attachment and GAD, consistent with research linking GAD to higher behavioral impulsiveness in response to distress (SaltersPedneault et al., 2006; Turk et al., 2005). Individuals with GAD may be unable to restrain their behavior, because they experience emotions more intensely. Heightened emotional intensity has been associated with more emotional expressivity (Gross \& John, 1997), and this expressivity may extend to behavior. Future research is needed to explore the link between impulse control, emotion intensity, and GAD symptoms, particularly given evidence suggesting that emotional reactivity fully explains the relation between anxious attachment and certain psychosocial problems (Wei, Vogel, et al., 2005).

Nonacceptance of one's emotions (Nonacceptance) fully mediated the relation between fearful avoidant attachment and GAD symptoms. Our results accord with prior research suggesting that GAD is linked to difficulties in accepting one's emotions and with fear of one's emotions (Mennin et al., 2005; Salters-Pedneault et al., 2006; Turk et al., 2005). There is some evidence, however, that Nonacceptance may be a nonspecific factor contributing to anxiety psychopathology (Mennin et al., 2009; Turk et al., 2005). Thus, other factors specifically related to fearful avoidant attachment, such as high avoidance and high anxiety, may be more useful in explaining the relation between this style of attachment and GAD.

The current study extends previous research on attachment and emotion regulation in adults, showing that emotion dysregu- lation is one avenue by which insecure attachment might result in depression and GAD symptoms. As such, our findings point to different dimensions of emotion dysregulation that might serve as targets for treatment, depending on whether a person suffers from symptoms of depression or GAD. More research is needed to further examine these relations. Extended knowledge about effective regulatory strategies would allow for the design of targeted preventive measures and interventions, at either the attachment (e.g., Lewis, Amini, \& Lannon, 2000; Reis \& Grenyer, 2004), emotion regulation (e.g., Mennin, 2004), or interpersonal (by developing effective support-seeking; e.g., Goldberg, 2000) levels.

\section{Limitations}

Several study limitations should be noted. Although ethnically diverse, our sample was comprised of undergraduate students, and thus may not accurately reflect the attachment styles or emotion regulation techniques of adults involved in longterm relationships and with considerable life experience. Presumably, attachment styles and emotion regulation techniques would be more stable in an older sample (e.g., Larcom \& Isaacowitz, 2009; Orgeta, 2009). Second, the sample consisted mostly of female subjects, and thus these findings may generalize primarily to females. Having only 54 male subjects in the sample precluded analyses of these relations separately for men. Furthermore, this study used a nonclinical sample, and results may thus not generalize to individuals experiencing clinical levels of depression or GAD. In addition, the cross-sectional nature of the study limits the ability to determine directionality of relations. For instance, GAD is a chronic disorder in which nearly $50 \%$ of cases have an age of onset prior to adulthood (Campbell, Brown, \& Grisham, 2003). Rather than adult attachment influencing GAD symptoms, it is possible that the presence of GAD contributes to adult attachment style. Finally, the study consisted entirely of self-report measures. It is possible that the relations among variables might be accounted for by shared method variance. Observational or behavioral measures of attachment and emotion regulation would have strengthened the study design.

\section{Conclusions}

In sum, this study examined the relation between attachment style, emotion dysregulation, and symptoms of depression and GAD. Insecure attachment styles were associated with greater emotion dysregulation and with higher levels of depression and GAD symptoms. Perceived access to effective emotion regulation strategies (Strategies) was the only emotion dysregulation dimension statistically mediating the relation between attachment styles and depression symptoms. Meanwhile, three emotion regulation domains-Strategies, nonacceptance of negative emotions (Nonacceptance), and inability to control impulsive behavior when distressed (Impulse)-mediated the relation between attachment styles and GAD symptoms. These findings underscore the complexity of the associations between adult attachment style, emotion regulation, and vulnerability to depressive and anxious symptoms. They also emphasize the need for future studies to tease apart these dependencies, to 
identify risk and protective factors, and to develop targeted interventions for GAD and depression.

Keywords: young adults; college students; adult attachment style; attachment anxiety; emotion dysregulation; generalized anxiety disorder; depression; rumination

\section{References}

Aldao, A., Nolen-Hoeksema, S., \& Schweizer, S. (2010). Emotion regulation strategies across psychopathology: A meta-analytic review. Clinical Psychology Review, 30, 217-237.

American Psychiatric Association. (1994). Diagnostic and statistical manual of mental disorders (4th ed.). Washington, DC: Author.

Anderson, E. R., \& Hope, D. A. (2008). A review of the tripartite model for understanding the link between anxiety and depression in youth. Clinical Psychology Review, 28, 275-287.

Baron, R. M., \& Kenny, D. A. (1986). The moderator-mediator variable distinction in social psychological research: Conceptual, strategic, and statistical considerations. Journal of Personality and Social Psychology, 51, 1173-1182.

Bartholomew, K., \& Horowitz, L. M. (1991). Attachment styles among young adults: A test of a four-category model. Journal of Personality and Social Psychology, 61, 226-244.

Beck, A. T., Steer, R. A., \& Brown, G. K. (1996). Manual for the Beck Depression Inventory-II. San Antonio, TX: Psychological Corporation.

Bifulco, A., Kwon, J., Jacobs, C., Moran, P. M., Bunn, A., \& Beer, N. (2006). Adult attachment style as mediator between childhood neglect/abuse and adult depression and anxiety. Social Psychiatry and Psychiatric Epidemiology, 41, 796-805.

Borkovec, T. D., Alcaine, O. M., \& Behar, E. (2004). Avoidance theory of worry and generalized anxiety disorder. In R. Heimberg, C. Turk, \& D. Mennin (Eds.), Generalized anxiety disorder: Advances in research and practice (pp. 77-108). New York, NY: Guilford Press.

Bouthillier, D., Julien, D., Dubé, M., Bélanger, I., \& Hamelin, M. (2002). Predictive validity of adult attachment measures in relation to emotion regulation behaviors in marital interactions. Journal of Adult Development, 9, 291-305.

Bowlby, J. (1982/1969). Attachment and loss: Vol. 1. Attachment (2nd ed.). New York, NY: Basic Books.

Breitholtz, E., Johansson, B., \& Öst, L. G. (1999). Cognitions in generalized anxiety disorder and panic disorder patients: A prospective approach. Behaviour Research and Therapy, 37, 533-544.

Byrne, B. N. (2001). Structural equation modeling with AMOS: Basic concepts, applications, and programming. Mahwah, NJ: Lawrence Erlbaum \& Associates.

Campbell, L. A., Brown, T. A., \& Grisham, J. R. (2003). The relevance of age of onset to the psychopathology of generalized anxiety disorder. Behavior Therapy, 34, 31-48.

Cassidy, J. (1994). Emotion regulation: Influences of attachment relationships. Monographs of the Society for Research in Child Development, 59, 228-249.

Clark, L. A., \& Watson, D. (1991). Tripartite model of anxiety and depression: Psychometric evidence and taxonomic implications. Journal of Abnormal Psychology, 100, 316-336.

Cole, P. M., Martin, S. E., \& Dennis, T. A. (2004). Emotion regulation as a scientific construct: Methodological challenges and directions for child development research. Child Development, 75, 317-333.

Conradi, H. J., \& de Jonge, P. (2009). Recurrent depression and the role of adult attachment: A prospective and a retrospective study. Journal of Affective Disorders, 116, 93-99.

Cooper, L. M., Shaver, P. R., \& Collins, N. L. (1998). Attachment styles, emotion regulation, and adjustment in adolescence. Journal of Personality and Social Psychology, 74, 1380-1397.
Cooper, R. M., Rowe, A. C., Penton-Voak, I. S., \& Ludwig, C. (2009). No reliable effects of emotional facial expression, adult attachment orientation, or anxiety on the allocation of visual attention in the spatial cueing paradigm. Journal of Research in Personality, 43, 643-652.

Cougle, J. R., Fitch, K. E., Fincham, F. D., Riccardi, C. J., Keough, M. E., \& Timpano, K. R. (2012). Excessive reassurance-seeking and anxiety pathology: Tests of incremental associations and directionality. Journal of Anxiety Disorders, 26, 117-125.

Dennis, T. A. (2007). Interactions between emotion regulation strategies and affective style: Implications for trait anxiety versus depressed mood. Motivation and Emotion, 31, 200-207.

Dinero, R. E., Conger, R. D., Shaver, P. R., Widaman, K. F., \& Larsen-Rife, D. (2008). Influence of family of origin and adult romantic partners on romantic attachment security. Journal of Family Psychology, 22, 622-632.

Dosois, D. J. A., Dobson, K. S., \& Ahnberg, J. L. (1998). A psychometric evaluation of the Beck Depression Inventory-II. Psychological Assessment, 10, 83-89.

Ehring, T., Fischer, S., Schnülle, J., Bösterling, A., \& Tuschen-Caffier, B. (2008). Characteristics of emotion regulation in recovered depressed versus never depressed individuals. Personality and Individual Differences, 44, 1574-1584.

Ehring, T., Tuschen-Caffier, B., Schnülle, J., Fischer, S., \& Gross, J. J. (2010). Emotion regulation and vulnerability to depression: Spontaneous versus instructed use of emotion suppression and reappraisal. Emotion, 110, 563-572.

Feeney, B. C., \& Collins, N. L. (2001). Predictors of caregiving in adult intimate relationships: An attachment theoretical perspective. Journal of Personality and Social Psychology, 80, 972-994.

Gasperini, M., Battaglia, M., Diaferia, G., \& Bellodi, L. (1990). Personality features related to generalized anxiety disorder. Comprehensive Psychiatry, 31, 363-368.

Gentzler, A. L., Kerns, K., \& Keener, E. (2010). Emotional reactions and regulatory responses to negative and positive events: Associations with attachment and gender. Motivation and Emotion, 34, 78-92.

Gillath, O., Bunge, S. A., Shaver, P. R., Wendelken, C., \& Mikulincer, M. (2005). Attachment-style differences in the ability to suppress negative thoughts: Exploring the neural correlates. NeuroImage, 28, 835847.

Goldberg, C. (2000). Basic emotional communication (BEC) for intimate relating: Guidelines for dialogue. Journal of Contemporary Psychotherapy, 30, 61-70.

Gratz, K. L., \& Roemer, L. (2004). Multidimensional assessment of emotion regulation and dysregulation: Development, factor structure, and initial validation of the difficulties in emotion regulation scale. Journal of Psychopathology and Behavioral Assessment, 26, 41-54.

Griffin, D., \& Bartholomew, K. (1994). Models of the self and other: Fundamental dimensions underlying measures of adult attachment. Journal of Personality and Social Psychology, 67, 430-445.

Gross, J. J. (1998). The emerging field of emotion regulation: An integrative review. Review of General Psychology, 2, 271-299.

Gross, J. J., \& John, O. P. (1997). Revealing feelings: Facets of emotional expressivity in self-reports, peer ratings, and behavior. Journal of Personality and Social Psychology, 72, 435-448.

Gross, J. J., \& John, O. P. (2003). Individual differences in two emotion regulation processes: Implications for affect, relationships, and wellbeing. Journal of Personality and Social Psychology, 85, 348-362.

Hankin, B. L., Kassel, J. D., \& Abela, J. R. Z. (2005). Adult attachment dimensions and specificity of emotional distress symptoms: Prospective investigations of cognitive risk and interpersonal stress generation as mediating mechanisms. Personality and Social Psychology Bulletin, 31, 136-151.

Hazan, C., \& Shaver, P. (1987). Romantic love conceptualized as an attachment process. Journal of Personality and Social Psychology, 52, $511-524$. 
Hesse, E. (2008). The adult attachment interview: Protocol, method of analysis, and empirical studies. In J. Cassidy \& P. R. Shaver (Eds.), Handbook of attachment: Theory, research, and clinical applications (2nd ed., pp. 552-598). New York, NY: Guilford Press.

Kerns, K. A., Abraham, M. M., Schlegelmilch, A., \& Morgan, T. A. (2007). Mother-child attachment in later middle childhood: Assessment approaches and associations with mood and emotion regulation. Attachment \& Human Development, 9, 33-53.

Kessler, R. C., Nelson, C. B., McGonagle, K. A., Liu, J., Swartz, M., \& Blazer, D. G. (1996). Comorbidity of DSM-III-R major depressive disorder in the general population: Results from the US National Comorbidity Survey. British Journal of Psychiatry, 168, 17-30.

Kobak, R. R., \& Sceery, A. (1988). Attachment in late adolescence: Working models, affect regulation, and representations of self and others. Child Development, 59, 135-146.

Larcom, M. J., \& Isaacowitz, D. M. (2009). Rapid emotion regulation after mood induction: Age and individual differences. Journals of Gerontology. Series B, Psychological Sciences and Social Sciences, 64B, 733-741.

Lewis, T., Amini, F., \& Lannon, R. (2000). A general theory of love. New York, NY: Random House.

Mennin, D. S. (2004). Emotion regulation therapy for generalized anxiety disorder. Clinical Psychology and Psychotherapy, 11, 17-29.

Mennin, D. S., Heimberg, R. G., Turk, C. L., \& Fresco, D. M. (2005). Preliminary evidence for an emotion dysregulation model of generalized anxiety disorder. Behaviour Research and Therapy, 43, 12811310.

Mennin, D. S., Holaway, R. M., Fresco, D. M., Moore, M. T., \& Heimberg, R. G. (2007). Delineating components of emotion and its regulation in anxiety and mood psychopathology. Behavior Therapy, 38, 284-302.

Mennin, D. S., McLaughlin, K. A., \& Flanagan, T. J. (2009). Emotion regulation deficits in generalized anxiety disorder, social anxiety disorder, and their co-occurrence. Journal of Anxiety Disorders, 23, 866-871.

Mickelson, K. D., Kessler, R. C., \& Shaver, P. R. (1997). Adult attachment in a nationally representative sample. Journal of Personality and Social Psychology, 73, 1092-1106.

Mikulincer, M. (1995). Attachment style and the mental representation of the self. Journal of Personality and Social Psychology, 69, 12031215.

Mikulincer, M., \& Orbach, I. (1995). Attachment styles and repressive defensiveness: The accessibility and architecture of affective memories. Journal of Personality and Social Psychology, 68, 917-925.

Mikulincer, M., Shaver, P. R., \& Pereg, D. (2003). Attachment theory and affect regulation: The dynamics, development, and cognitive consequences of attachment-related strategies. Motivation and Emotion, $27,77-102$.

Miranda, R., Fontes, M., \& Marroquín, B. (2008). Cognitive contentspecificity in future expectancies: Role of hopelessness and intolerance of uncertainty in depression and GAD symptoms. Behaviour Research and Therapy, 46, 1151-1159.

Mogg, K., Millar, N., \& Bradley, B. P. (2000). Biases in eye movements to threatening facial expressions in generalized anxiety disorder and depressive disorder. Journal of Abnormal Psychology, 109, 695-704.

Newman, M. G., Zuellig, A. R., Kachin, K. E., Constantino, M. J., Przeworsky, A., Erickson, T., \& Cashman-McGrath, L. (2002). Preliminary reliability and validity of the generalized anxiety disorder questionnaire-IV: A revised self-report diagnostic measure of generalized anxiety disorder. Behavior Therapy, 33, 215-233.

Nolen-Hoeksema, S., Larson, J., \& Grayson, C. (1999). Explaining the gender difference in depressive symptoms. Journal of Personality and Social Psychology, 77, 1061-1072.
Orgeta, V. (2009). Specificity of age differences in emotion regulation. Aging and Mental Health, 13, 818-826.

Preacher, K. J., \& Leonardelli, G. J. (2001). Calculation for the Sobel test. Retrieved from http://www.quantpsy.org/sobel/sobel.htm

Reis, S., \& Grenyer, B. F. (2004). Fearful attachment, working alliance and treatment response for individuals with major depression. Clinical Psychology and Psychotherapy, 11, 414-424.

Roemer, L., Salters, K., Raffa, S. D., \& Orsillo, S. M. (2005). Fear and avoidance of internal experiences in GAD: Preliminary tests of a conceptual model. Cognitive Therapy and Research, 29, 71-88.

Roisman, G. I., Holland, A., Fortuna, K., Fraley, R. C., Clausell, E., \& Clarke, A. (2007). The adult attachment interview and self-reports of attachment style: An empirical rapprochement. Journal of Personality and Social Psychology, 92, 678-697.

Roisman, G. I., Tsai, J. L., \& Chiang, K. S. (2004). The emotional integration of childhood experience: Physiological, facial expressive, and self-reported emotional response during the adult attachment interview. Developmental Psychology, 40, 776-789.

Salters-Pedneault, K., Roemer, L., Tull, M. T., Rucker, L., \& Mennin, D. S. (2006). Evidence of broad deficits in emotion regulation associated with chronic worry and generalized anxiety disorder. Cognitive Therapy and Research, 30, 469-480.

Simonelli, L., Ray, W., \& Pincus, A. L. (2004). Attachment models and their relationships with anxiety, worry and depression. Counseling and Clinical Psychology Journal, 1, 107-118.

Slee, N., Garnefski, N., Spinhoven, P., \& Arensman, E. (2008). The influence of cognitive emotion regulation strategies and depression severity on deliberate self-harm. Suicide and Life-Threatening Behavior, 38, 274-286.

Sobel, M. E. (1982). Asymptotic intervals for indirect effects in structural equation models. In S. Leinhart (Ed.), Sociological methodology (pp. 290-312). San Francisco, CA: Jossey-Bass.

Sroufe, L. A. (2005). Attachment and development: A prospective, longitudinal study from birth to adulthood. Attachment \& Human Development, 7, 349-367.

Tasca, G. A., Szadkowski, L., Illing, V., Trinneer, A., Grenon, R., Demidenko, N., ... Bissada, H. (2009). Adult attachment, depression, and eating disorder symptoms: The mediating role of affect regulation strategies. Personality and Individual Differences, 47, 662 $-667$.

Tull, M. T., Barrett, H. M., McMillan, E. S., \& Roemer, L. (2007). A preliminary investigation of the relationship between emotion regulation difficulties and posttraumatic stress symptoms. Behavior Therapy, 38, 303-313.

Tull, M. T., Stipelman, B. A., Salters-Pedneault, K., \& Gratz, K. L. (2009). An examination of recent non-clinical panic attacks, panic disorder, anxiety sensitivity, and emotion regulation difficulties in the prediction of generalized anxiety disorder in an analogue sample. Journal of Anxiety Disorders, 23, 275-282.

Turk, C. L., Heimberg, R. G., Luterek, J. A., Mennin, D. S., \& Fresco, D. M. (2005). Emotion dysregulation in generalized anxiety disorder: A comparison with social anxiety disorder. Cognitive Therapy and Research, 29, 89-106.

Wei, M., Mallinckrodt, B., Larson, L. M., \& Zakalik, R. A. (2005). Adult attachment, depressive symptoms, and validation from self versus others. Journal of Counseling Psychology, 52, 368-377.

Wei, M., Vogel, D. L., Ku, T.-Y., \& Zakalik, R. A. (2005). Adult attachment, affect regulation, negative mood, and interpersonal problems: The mediating roles of emotional reactivity and emotional cutoff. Journal of Counseling Psychology, 52, 14-24.

Whisman, M. A., Perez, J. E., \& Ramel, W. (2000). Factor structure of the Beck Depression Inventory - Second Edition (BDI-II) in a student sample. Journal of Clinical Psychology, 56, 545-551. 